\title{
Antihyperglycemic and Anti-hyperlipidemic Effect of Herbamed, A Herbal Formulation in Alloxan-Induced Diabetic Rats
}

\author{
Isitua $\mathrm{CC}^{1 *}$, Akinyemi $\mathrm{AJ}^{2}$, Akharaiyi $\mathrm{FC}^{1}$, Olubiyi $\mathrm{OO}^{3}$, Anadozie $\mathrm{SO}^{2}$ and Olayide $\mathrm{II}^{2}$ \\ ${ }^{1}$ Department of biological sciences, Afe Babalola University Ado-Ekiti, Nigeria \\ ${ }^{2}$ Department of Chemical Sciences, Afe Babalola University Ado-Ekiti, Nigeria \\ ${ }^{3}$ Department of Pharmacology and Therapeutics, College of Medicine and Health Sciences, Afe Babalola University Ado-Ekiti, Nigeria \\ *Corresponding author: Isitua Chinwe Christy, Department of Biological Sciences, College of Sciences, Afe Babalola University Ado-Ekiti (ABUAD), \\ Ekiti State, Nigeria, Tel: +2348023372109; Email: isituacc@abuad.edu.ng/ christykings@yahoo.com
}

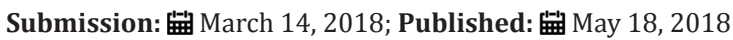

\begin{abstract}
Diabetes mellitus is a metabolic disorder characterized by hyperglycemia and its occurrence is increasing fast in most of the countries. Herbal medicine derived from plant extracts have been utilized increasingly for the treatment of various disorders like diabetes mellitus. The present study was designed to evaluate the anti diabetic activity of 'Herbamed', a herbal formulation composed of Vernonia amygdalina, Ocimum gratissimum, Zingiber officinale and Allium sativum in alloxan-induced diabetic rats model. Alloxan $(150 \mathrm{mg} / \mathrm{kg})$ was used to induce diabetes in rats and the blood glucose levels were estimated by using glucometer. The herbal formulation known as 'Herbamed' was administered to diabetic rats for 7 days at 0.5 and $1.0 \mathrm{~mL}$ $(250 \mathrm{mg} / \mathrm{kg}$ rat). The herbal formulation produced a significant reduction $(\mathrm{P}<0.05)$ of blood glucose levels in diabetic rats at both doses tested. It also showed a beneficial effect on the lipid profile and liver function test in alloxan induced diabetic rats. These results showed that 'Herbamed' exhibits antihyperglycemic and antihyperlipidemic activities in diabetic rats.
\end{abstract}

Keywords: Diabetes mellitus; Herbal medicine; Antihyperglycemic; Alloxan; Antihyperlipidemic

\section{Introduction}

Diabetes mellitus (DM) is the most common degenerative disease and has been shown to affects about $10 \%$ of the world population [1]. DM is a metabolic disorder characterized by hyperglycaemia, abnormal lipid and protein metabolism along with specific long-term complications affecting the brain, liver, retina and kidney [2]. Hyperglycaemia has been implicated in the development and progression of the complications of diabetes mellitus. The pathogenesis of DM is managed by insulin and oral administration of anti-diabetic drugs such as metformin, acarbose, sulfonylureas and biguanides. Unfortunately, all these drugs have a number of side effects and some of the oral synthetic hypoglycaemic agents have been successful in controlling long-term microvascular and macrovascular complications. Hence, recent research focuses on medicinal plants with little/or no side effects.

For some decades now, diabetics have been treated with medicinal plants based on traditional medicine information. Several plant species have been discovered to possess hypoglycemic effects [3-5]. Despite the presence of anti-diabetic medicines in the market, the search for more effective and safer hypoglycemic agents has continued to be an important area of research. Many traditional plant drugs and herbal formulation are frequently considered to be less toxic and freer from side effects than synthetic one. Based on the WHO 1980 recommendations, hypoglycaemic agents of plant origin used in traditional medicine are important. In the traditional system of Indian medicine, plant formulation and combined extracts of plants are used as drug of choice rather than individual. Various herbal formulations such as diamed are well known for their anti-diabetic effects [6,7].

'Herbamed' is a polyherbal drug composed of four medicinal plants (Table 1). There is no report available in the literature for the anti-diabetic effect of 'herbamed' in alloxan-induced diabetic rats. The present investigation was undertaken to study the antihyperglycemic effect of 'herbamed', a herbal formulation, on changes in blood glucose, plasma lipid profile and hepatic function test in alloxan-induced diabetic rats. The effects produced by this formulation on different parameters were compared with metformin, an anti-diabetic drug. 
Table 1: 'Herbamed' composition and parts used

\begin{tabular}{|c|c|c|c|c|}
\hline S/N & Botanical Name & Common Name & Family & Part Used \\
\hline 1 & Vernonia amygdalina & Bitter leaf & Asteraceae & Leaves \\
\hline 2 & Ocimum gratissimum & Clove basil & Lamiaceae & Leaves \\
\hline 3 & Zingiber officinale & Ginger & Zingiberaceae & Rhizome \\
\hline 4 & Allium sativum & Garlic & Amaryllidaceae & Root \\
\hline
\end{tabular}

\section{Materials and Methods}

\section{Drugs and chemicals}

Drugs and chemicals used such as Alloxan, metformin, Tris- $\mathrm{HCl}$ buffer and sodium chloride were obtained from Sigma-Aldrich (St. Louis, MO, USA. Except stated otherwise, all other chemicals and reagents were of analytical grades and the water was glass distilled. Kits used for this experiment were purchased from RANDOX Laboratories Ltd., Crumlin, County Antrim, UK). Alloxan was dissolved in saline solution for intraperitoneal administration and metformin was dissolved in distilled water for oral administration.

\section{Plant samples}

Vernonia amygdalina, Ocimum gratissimum, Zingiber officinale and Allium sativum were collected freshly from Afe Babalola University (ABUAD) farms, Ado-Ekiti, Nigeria. Voucher specimens were deposited at the herbarium of the Botany Department, Ekiti State University, Ekiti State, Nigeria.

\section{'Herbamed' preparation}

'Herbamed' was prepared on the basis of an ayurvedic antidiabetic formulation proposed by Pandey et al. [8]. One hundred grams $(100 \mathrm{~g})$ of Vernonia amygdalina and Ocimum gratissimum as well as ten grams $(10 \mathrm{~g})$ of Zingiber officinale and Allium sativum were blended in $20 \mathrm{~mL}$ of distilled water and filtrate was collected by the method of continuous cold extraction.

\section{Experimental animals}

Male albino Wistar rats (180-250g) bred in the Central Animal House, College of Medicine, Afe Babalola University, were used. The animals were fed on a standard pellet diet (ABUAD Farms, Nigeria) and water was freely available.

\section{Experimental induction of diabetes}

The rats were injected intraperitoneally with alloxan monohydrate dissolved in sterile normal saline at a dose of $150 \mathrm{mg} /$ $\mathrm{kg}$. After three days, the rats which had developed moderate diabetes and hyperglycaemia with a blood glucose range $\geq 250 \mathrm{mg} /$ $\mathrm{dL}$, were used for the experiment. Blood was collected from the eyes (venous pool)

\section{Experimental design}

In this experiment a total of 30 rats $(24$ diabetic surviving rats, 6 normal rats) were used. Diabetes was induced in rats before the start of the experiment. The rats were divided into five groups $(n=6)$ after the induction of diabetes. Group 1 was the normal untreated rats. Group 2 was the diabetic untreated rats. Group 3 was the diabetic rats given 'Herbamed' $\left(0.5 \mathrm{~mL}(0.25 \mathrm{~g}) \mathrm{kg}^{-1}\right)$ in aqueous solution daily using an intragastric tube for 7 days. Group 4 was the diabetic rats given 'Herbamed' $\left(1.0 \mathrm{~mL}(0.25 \mathrm{~g}) \mathrm{kg}^{-1}\right)$ in aqueous solution daily using an intragastric tube for 7 days. Group 5 was the diabetic rats given metformin $(500 \mathrm{mg} / \mathrm{kg})$ in aqueous solution daily using an intragastric tube for 7 days. After the end of the experiment, the rats were killed by decapitation. Blood was collected in an anti-coagulant tube containing EDTA and the serum obtained was used for the estimation of some biochemical parameters.

\section{Biochemical assays}

For the determination of biochemical assays, the serum obtained was used for the determination of lipid profile (Total cholesterol, LDL-C and Triglycerides) using commercial available kits from RANDOX Laboratories Ltd., Crumlin, County Antrim, UK.

\section{Statistical analysis}

All data were expressed as mean \pm standard error of mean (S.E.M.). The statistical analysis used was one-way ANOVA, followed by the post hoc Tukey's test, $\mathrm{p}<0.05$ was considered to represent a significant difference in both analyses used.

Results

\section{Effect of 'herbamed' on blood glucose level in alloxan-induced diabetic rats}

Table 2: Change in blood glucose level.

\begin{tabular}{|c|c|c|c|}
\hline Experimental Groups & Initial Glucose Level (mg/dl) & Final Glucose Level (mg/d) & Decrease in Glucose Level (\%) \\
\hline Group 1 & $111.2 \pm 1.6$ & $106.7 \pm 6.7$ & $3.03 \pm 0.02$ \\
\hline Group 2 & $347.3 \pm 14.3$ & $400.1 \pm 12.0$ & $-15.3 \pm 2.1$ \\
\hline Group 3 & $281.0 \pm 8.1$ & $256.3 \pm 6.3$ & $8.78 \pm 1.4$ \\
\hline Group 4 & $309.1 \pm 9.9$ & $189.7 \pm 8.7$ & $38.6 \pm 4.1$ \\
\hline Group 5 & $310.5 \pm 10.5$ & $217.7 \pm 11.7$ & $29.9 \pm 3.4$ \\
\hline
\end{tabular}

Values represent mean \pm SEM $(n=6)$. 


\section{Key:}

Group 1-control

Group 2-diabetic untreated rats.

Group 3-diabetic rats given Herbamed $\left(0.5 \mathrm{~mL}(0.25 \mathrm{~g}) \mathrm{kg}^{-1}\right)$

Group 4-diabetic rats given Herbamed (1.0mL $\left.(0.25 \mathrm{~g}) \mathrm{kg}^{-1}\right)$

Group 5-diabetic rats given metformin $(500 \mathrm{mg} / \mathrm{kg})$

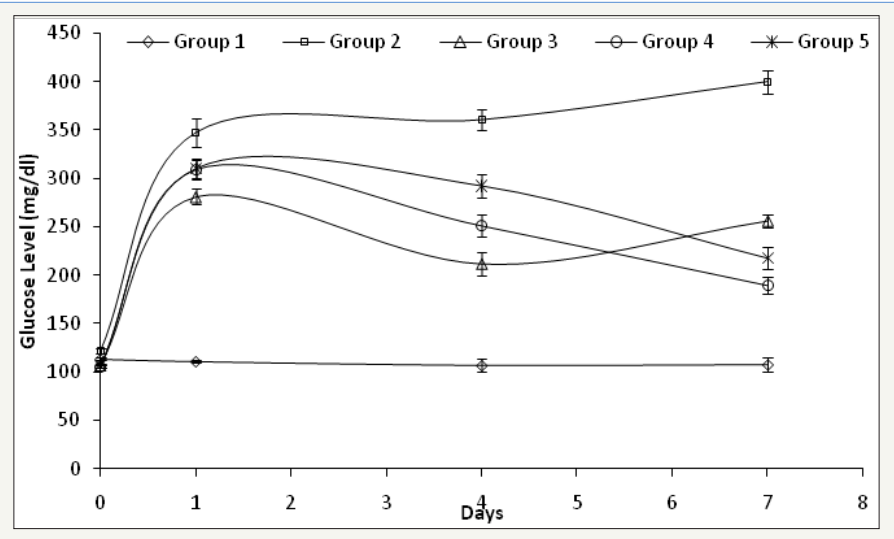

Figures 1: Effect of herbamed on blood glucose level in alloxan-induced diabetic rats

\section{Key:}

Group 1-control

Group 2-diabetic untreated rats.

Group 3-diabetic rats given Herbamed $\left(0.5 \mathrm{~mL}(0.25 \mathrm{~g}) \mathrm{kg}^{-1}\right)$

Group 4-diabetic rats given Herbamed $\left(1.0 \mathrm{~mL}(0.25) \mathrm{kg}^{-1}\right)$

Group 5-diabetic rats given metformin $(500 \mathrm{mg} / \mathrm{kg})$

(Figure 1) represents the effect of 'herbamed', an herbal formulation on blood glucose level in alloxan-induced diabetic rats. The result revealed that alloxan caused a significant $(\mathrm{P}<0.05)$ increase in blood glucose level when compared with the control. However, the herbal formulation as well as the anti-diabetic drug (metformin) prevented this alteration by causing a significant $(\mathrm{P}<0.05)$ decrease in blood glucose level in a dose-dependent manner when compared with the diabetic control group. Taking into consideration the change in blood glucose level in (Table 2), our herbal formulation at higher dose compare favorably with the anti-diabetic drug (metformin) tested in this experiment.

\section{Discussion}

Alloxan, a beta-cytotoxin, has been demonstrated to induce 'chemical diabetes' (alloxan diabetes) in a wide variety of animal species by damaging the insulin-secreting cells of the pancreas [9]. This damages a large number of beta-cells, resulting in decrease in endogenous insulin release. Alloxan administered rats therefore become hyperglycaemic in a short period of time, followed by a hepatic glucose over production. In the present study, we observed

Table 3: Effect of herbamed on serum lipid profile in alloxan-induced diabetic rats. a significant increase in blood glucose levels after alloxan injection of the rats. Etuk et al. \& Adeyi et al. [10,11] attributed this increase in glucose levels to the reactive oxygen species induced by alloxan; in conjunction with a simultaneous massive increase in cytosolic calcium concentrations that led to a rapid destruction of pancreatic islet cells and a concomitant reduction in synthesis/release of insulin.

Interestingly, treatment with our herbal formulation resulted in a significant decrease in blood glucose level in a dose-dependent manner (Figure 1). The possible contributing mechanism is hypothesized to be due to the potentiation of insulin secretion from $\beta$-islet cells and consequent enhanced transport of blood glucose to peripheral tissues. The ameliorative and preventive effect of herbamed against alloxan-induced diabetic rat may be attributed to the synergistic effect of the various phytocompounds present in the herbal mixtures. This findings support the traditional use of herbal formulation as an anti-diabetic herbal medicine. However, further studies should be carried out to confirm its exact mechanism of action and phytochemistry. Hypercholesterolemia is well-known as one of the most important risk factors of diabetes mellitus [12].

\begin{tabular}{|c|c|c|c|}
\hline Experimental Groups & Total Cholesterol & Triglyceride & LDL-Chol \\
\hline Group 1 & $26.7 \pm 2.6 \mathrm{a}$ & $53.4 \pm 6.7 \mathrm{a}$ & $10.6 \pm 1.2 \mathrm{a}$ \\
\hline Group 2 & $41.9 \pm 1.3 \mathrm{~b}$ & $121.1 \pm 9.7 \mathrm{~b}$ & $24.3 \pm 4.1 \mathrm{~b}$ \\
\hline Group 3 & $27.4 \pm 2.1 \mathrm{a}$ & $54.3 \pm 6.3 \mathrm{a}$ & $10.8 \pm 1.4 \mathrm{a}$ \\
\hline
\end{tabular}




\begin{tabular}{|c|c|c|c|}
\hline Group 4 & $28.3 \pm 2.4 \mathrm{a}$ & $45.1 \pm 3.1 \mathrm{a}$ & $11.3 \pm 4.1 \mathrm{a}$ \\
\hline Group 5 & $37.9 \pm 5.4 \mathrm{a}$ & $51.5 \pm 4.4 \mathrm{a}$ & $10.3 \pm 2.4 \mathrm{a}$ \\
\hline
\end{tabular}

Values represent mean \pm SEM $(n=6)$.

Values with the same superscript letter along the column are not significantly different at $\mathrm{P}<0.05$

Key:

Group 1-control

Group 2-diabetic untreated rats.

Group 3-diabetic rats given Herbamed $\left(0.5 \mathrm{~mL}(0.25 \mathrm{~g}) \mathrm{kg}^{-1}\right)$

Group 4-diabetic rats given Herbamed $\left(1.0 \mathrm{~mL}(0.25 \mathrm{~g}) \mathrm{kg}^{-1}\right)$

Group 5-diabetic rats given metformin $(500 \mathrm{mg} / \mathrm{kg})$

It has been shown that hypercholesterolemia increases oxidative stress and leads to lipid peroxidation. It has been suggested that lowering circulating cholesterol levels can reduce the risk of cardiovascular diseases and diabetes mellitus. In the present study, we observed that alloxan treatment altered lipid profile in diabetic rats as shown by a significant $(\mathrm{P}<0.05)$ increase in total cholesterol, triglyceride and LDL-cholesterol levels when compared with the control (Table 3). However, our herbal formulation tested caused a significant $(\mathrm{p}<0.05)$ decrease in total cholesterol, triglyceride and LDL-cholesterol levels when compared with the induced group. The hypocholesterolemic effect of the herbal formulation could be due to high polyphenols in the herbal constituents. It is well-known that plasma cholesterol concentration can be regulated by cholesterol biosynthesis, cholesterol removal from the circulatory system, the absorption of dietary cholesterol, and its excretion via bile and feces [13].

\section{Conclusion}

In the present study, our results demonstrated that 'herbamed', an herbal formulation composed of Vernonia amygdalina, Ocimum gratissimum, Zingiber officinale and Allium sativum exhibit antihyperglycemic and antihyperlipidemic properties in alloxaninduced diabetic rats model. This finding supports the traditional use of herbal formulation as an anti-diabetic herbal medicine. However, further studies should be carried out to confirm its exact mechanism of action and phytochemistry.

\section{Conflict of Interest}

No conflict of interest to be stated for any of the authors.

\section{Acknowledgement}

The authors are thankful to the Directorate of Technological Development (DTD) Afe Babalola University Ado-Ekiti, for funding this research.

\section{References}

1. Burke JP, Williams K, Narayan KMV, Leibson C, Haffner SM, Stern MP, et al. (2003) A population perspective on diabetes prevention: whom should we target for preventing weight gain. Diabetes Care 26(7): 1999-2004.

2. Pari L, Saravanan R (2004) Antidiabetic effect of diasulin, a herbal drug, on blood glucose, plasma insulin and hepatic enzymes of glucose metabolism in hyperglycaemic rats. Diabetes Obes Metab 6(4): 286-292.

3. Barbosa-Filho JM, Vasconcelos T, Alencar AA, Batista LM, Oliveira R, et al. (2005) Plants and their active constituents from South, Central, and North America with hypoglycaemic activity. Revista Brasileira de Farmacognosia 15(4): 392-413.

4. Gurib-Fakim A (2006) Medicinal plants: traditions of yesterday and drugs of tomorrow. Mol Aspects Med 27(1): 1-93.

5. Lans CA (2006) Ethnomedicines used in Trinidad and Tobago for urinary problems and diabetes mellitus J Ethnobiol Ethnomed 2: 45.

6. Pari L, Ramakrishnan R, Venkateswaran S (2001) Antihyperglycaemic effect of Diamed, a herbal formulation in experimental diabetes in rats. J Pharm Pharmacol 53(8): 1139-1143.

7. Pari L, Saravanan G (2002) Antidiabetic effect of cogent db, a herbal drug in alloxan induced diabetes mellitus. Comp Biochem Physiol C Toxicol Pharmacol 131(1): 19-25.

8. Pandey VN, Rajagopalan SS, Chowdhorry DP (1995) An effective ayurvedic hypoglycemic formulation. Journal of Research in Ayurveda and Pharmacy 16: 1-14.

9. Martinez JA, Milagro FI (2000) Effect of the oral administration of a b3adrenergic agonist on lipid metabolism in alloxan diabetic rats. J Pharm Pharmacol 52(7): 851-856.

10. Etuk E, Muhammed B (2010) Evidence-based analysis of chemical method of induction of diabetes mellitus in experimental animals. Asian Journal of Experimental Biology 1: 331-336.

11. Adeyi A, Idowu B, Mafiana C, Oluwalana S, Ajayi O, et al. (2012) Rat model of food-induced non-obese-type 2 diabetes mellitus: comparative pathophysiology and histopathology. Int J Physiol Pathophysiol Pharmacol 4(1): 51-58.

12. Cox DA, Cohen ML (1996) Effects of oxidized low-density lipoprotein on vascular contraction and relaxation: clinical and pharmacological implications in atherosclerosis. Pharmacol Rev 48(1): 3-19.

13. Kim HO, Lee MK, Jeon SM, Park MS (2003) The effect of supplementation of persimmon leaf extract on lipid and antioxidant metabolism in rats fed a high-cholesterol diet. Nutritional Science 8: 2034-2040. 
Creative Commons Attribution 4.0 International License

For possible submissions Click Here

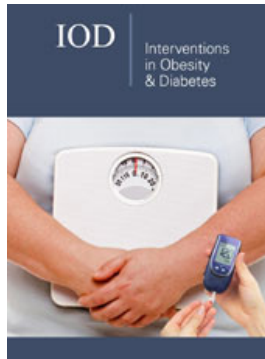

\section{Intervention in Obesity \& Diabetes}

\section{Benefits of Publishing with us}

- High-level peer review and editorial services

- Freely accessible online immediately upon publication

- Authors retain the copyright to their work

- Licensing it under a Creative Commons license

- Visibility through different online platforms 